\title{
EXPLORING THE DEVELOPMENT OF A BIM-ENABLED PROCESS FRAMEWORK FOR THE LCA OF RAII TRACKS
}

\author{
Anderson Akponeware ${ }^{1}$, Nashwan Dawood ${ }^{2}$, Sergio Rodriguez ${ }^{3}$, and Huda Dawood ${ }^{4}$
}

\begin{abstract}
A key 21st century infrastructure challenge is lowering cost and carbon over an infrastructure's whole lifecycle. But, accounting for the carbon footprint of a railway system is problematic due to the complexity of railway systems. Within the rail sector, there is still a lack of infrastructure frameworks which can accurately capture actions, interactions and associated processes by role actors during lifecycle analysis. Whilst there is increased focus to facilitate information digitisation in railway systems, there is a scarcity of literature which attempt to systematise and formalise the process of conducting lifecycle analysis (LCA) of railway systems. This paper identifies complexities associated with legacy LCA methodologies in the rail sector. It then proposes a methodology which applies design science techniques to facilitate the creation and re-use of information and data in a systematic way within a structured process workflow. The proposed methodology enables lifecycle information for a rail-track to be produced collaboratively in an integrated format. In addition, the proposed LCA technique allows the creation of LCA process workflows which can be deployed to the web, potentially integrating with other optioneering applications and BIM platforms.
\end{abstract}

Keywords: greenhouse gas emissions, rail tracks, BIM, LCA, process workflow.

\section{INTRODUCTION}

A key twenty-first century infrastructure challenge is lowering cost and carbon over an infrastructure's whole lifecycle; this is particularly crucial for the construction industry which has been reported to produce about $40 \%$ of total global waste (Poon 2007) and over $50 \%$ of UK greenhouse gas emissions (BSI 2016). In particular, the transport industry has contributed immensely to greenhouse gas emissions such as $\mathrm{CO}_{2}$ (Ortmeyer and Pillay 2001). Greenhouse gases (carbon dioxide, methane, water vapor, nitrous oxide, hydrofluorocarbons, chlorofluorocarbons and ozone) have the capacity to affect earth's energy balance as they absorb and emit its infrared radiation. These gases can have significant impacts on the environment such as climate change especially when intensive environmental human activities (e.g. building and infrastructure construction) promote their release into the atmosphere (Wong and Zhou 2015). This has resulted in numerous studies (Cuenot 2016) focused on quantifying the impact of greenhouse gases especially $\mathrm{CO}_{2}$ equivalents $(\mathrm{CO} 2-\mathrm{eq})$ during the construction of railway systems. Besides, there is acknowledged efforts by governments (HM Treasury 2013) highlighting the importance of green construction, and of industry (BSI 2016) setting out infrastructure targets. The focus by experts on how railway components affect the environment has also become more pronounced in lifecycle analysis (LCA) methodologies (Chester and Horvath 2009).

PhD student, Teesside University, SCEDT, Middlesbrough, UK, a.akponeware@tees.ac.uk

Prof, Teesside University, SCEDT, Middlesbrough, UK, n.n.dawood@tees.ac.uk

Dr, Teesside University, SCEDT, Middlesbrough, UK, s.rodriguez@tees.ac.uk

Dr, Teesside University, SCEDT, Middlesbrough, UK, h.dawood@tees.ac.uk 
Conventional LCA techniques use specialist LCA software which are also linked with LCA databases. The databases contain thousands of lifecycle inventory (LCI) datasets in different domains, including empirical building and construction energy, and material data. While adopting traditional LCA techniques for manufactured products may be straightforward, the contrast is true for process-based construction processes which often involve diverse project stakeholders and design teams. Meanwhile, fragmentation of processes in the construction industry have been addressed using Building Information Modelling (BIM) which can potentially improve design collaboration and promote design clash avoidance (Akponeware and Adamu 2017). BIM concept which can be traced back to Charles Eastman in the late 70's has no single acceptable definition. The authors of this paper have adopted the definitions provided by Succar et al. (2012) stated thus: "BIM refers to a set of interacting policies, processes and technologies that generate a methodology to manage the essential building design and project data in digital format throughout the building's life-cycle."; and the definition in EN ISO 19650-1:2018: "use of a shared digital representation of a built asset to facilitate design, construction and operation processes to form a reliable basis for decisions". These definitions underpin how BIM is becoming the de facto standard in efficient information management aligned to organizational policies and processes. Notably, the Digital Built Britain (DBB) strategy launched in 2016 stated that the key to achieving low carbon solutions is the migration to Building Information modelling (BIM) level 3 (open BIM). BIM level 3 promotes the creation and sharing of digital information in a file neutral format within integrated systems. This is a step higher than BIM level 2 which only encourages production of construction information in a digital format whether this be in proprietary software and disparate systems. BIM level 2 has already been mandated on publicly procured projects in the UK. The rail industry is currently moving towards improving environmental sustainability using BIM-enabled solutions (Kaewunruen and Lian 2019).

Elsewhere, the potential of BIM to efficiently manage lifecycle information have been explored in previous studies within the building domain (Najjar et al. 2017; Shin and Cho 2015; Anton and Diaz 2014). Within the rail sector, there is still a lack of infrastructure frameworks which can accurately capture actions, interactions and associated processes by role actors during lifecycle analysis. Further, there are limited studies which attempt to automate LCA workflow processes with data exchanges using an open BIM platform. Some significant problems with the state-of-the-art in the process of quantifying greenhouse gas emissions of a rail system over its life cycle are: the high inconsistencies in different approaches (Ortega et al. 2018; Cuenot 2016), data unavailability (Saxe et al 2016; Esters and Marinov 2014), and process complexity (Anton and Diaz 2014). This problem has led to the development of varying LCA methodologies and approaches which are well documented in literature (Cuenot 2016). This gap needs to be addressed in order to promote both integrated lifecycle assessments but also efficient management of carbon data and information exchanges; a further benefit being that it could potentially feed directly into related researches on Information Delivery Manual (IDM) developments in the rail sector. It was found in the literature that to tackle and control problems with complexities and to formalise interactions in process-based workflows, researchers employed the use of process modelling tools (e.g. see Grefen et al. 2018), and also proposed interaction models (Hoogervorst 2018; Dietz 2006) to specify ontological transactions and actor roles.

Based on this context, the objective of this paper is to propose an integrated platform for structured information and data exchange during the lifecycle analysis of a conventional rail-track by design participants. The realisation of this objective seeks to 
improve formalisation of LCA methodology and access to consistent and accurate data which can improve the quality of the data produced in LCA studies. The rest of the paper is structured as follows: first, a review of existing approaches to integrate lifecycle analysis (LCA) with BIM in the Architectural, Engineering, Construction and Operations (AECO) domain is presented in section 2. Then, based on the synthesis of the literature, section 3 presented a conceptual framework proposed for conducting the LCA of a rail track. Finally, section 4 presented the main conclusions of the paper.

\section{LITERATURE REVIEW}

\subsection{Lifecycle assessment applications in the rail industry}

LCA methodology which is the environmental branch of the three pillars of sustainability (environmental, social and economic) is the whole-of-life standardised and systematic assessment of the environmental impacts of products and processes (EN ISO 14040: 2006). The LCA methodology follows a 4-step process (EN ISO 14040: 2006; EN ISO 14044: 2006): Step 1-Goal and scope definition; Step 2-Inventory analysis; Step 3Impact assessment and Step 4-Interpretation phase. LCA studies in the construction industry is executed over the whole-of-life which consist of the following four separate lifecycle phases (BSI 2011): production phase (material extraction, transport and production), construction phase, use phase (including maintenance, refurbishment and replacement) and end-of-life phase (demolition, disposal, and decommissioning). LCA methodology is not new, haven initially been applied in product-based lifecycle analysis. The earliest application can be traced to the USA nearly six decades ago when it was used for the comparative evaluation of different beverage containers (Hauschild et al. 2005). Conducting an environmental analysis can help in the quantification of the impacts of greenhouse gases (or $\mathrm{CO} 2$ equivalents - CO2-eq) which are considered to have negative impacts on the environment.

Considering the rail sector, two LCA framings have been recognized when allocating greenhouse gas emissions, depending on whether it is time dependent. The approaches are consequential LCA and attributional LCA methodology (Chester et al., 2013). The former is focused on evaluating the time-dependent system-wide change in emissions, while the later employs average footprint values with the consequent risk of burdenshifting (Jackson and Brander, 2019). There has also been a progressive adoption of the LCA methodology in discrete application types. Thus, some studies have focused on tailpipe (rolling stock) emissions (Dalkic et al. 2017; Andrade and D'Agosto 2016; Pero et al. 2015; Esters and Marinov 2014); while others on non-tailpipe - that is, rail infrastructure emissions (Bressi et al. 2018; Krezo et al. 2018; Ortega et al. 2018); yet a third category on integrated assessments - that is, both tailpipe and non-tailpipe emissions (Saxe et al 2016; Westin and Kågeson 2012). There is evidence that studies on tailpipe emissions are more popular (Rocha et al. 2018; De Martinis and Corman 2018; Meynerts et al. 2017; Chester et al. 2013) owing largely to the ease of their validation via comparison with other modes of rail transport (Esters and Marinov 2014). Contemporary studies by Pritchard and Preston (2018) concluded that studies which ignore the contribution of rail infrastructure might be misleading. They found that studies which discount the emissions of rail infrastructure by only considering use-phase emissions might erroneously promote railway transport as having lower carbon impacts on the environment. This is a motivation for focusing on rail infrastructure (non-tailpipe) emissions in this paper. 
Environmental studies on railway systems (rolling stock and railway infrastructure) are relatively new. Some studies were focused on conventional rail types (Chester and Horvath 2009; Facanha and Horvath 2006). Regardless, the processes of quantifying the LCA of rail systems is not straightforward. For example, there is no consensus on the environmental impacts of HSR in the literature. Although, some studies (Dalkic et al. 2017; Jehanno et al. 2011; Akerman 2011) appeared to suggest that high speed rail is more sustainable in comparison to other modes of rail transport, there is contrary evidence suggesting otherwise (Bueno et al. 2017; Westin and Kågeson 2012). Also, the use of varying lifecycle quantification methodologies discussed earlier exacerbates the current issues.

The problem of the complexity of railway systems has further been identified in the literature. Stripple and Uppenberg (2010) identified seven sub-components of a railway system comprising of tracks, track foundations, tunnels, bridges, stations and terminals, freight and passenger trains, and electric power and control systems. The need for standardisation of approaches to quantify the lifecycle of such a complex system prompted a qualitative and comparative study of existing railway infrastructure LCA approaches (Cuenot 2016). The development of varying techniques and tools to tackle inherent complexities in the railway systems have led to further fragmentation in the Industry. The report by Cuenot (2016) found that the techniques employed in estimating the lifecycle carbon content of a railway is highly fragmented and weak. Ten different methodologies were identified in their study, and it was found that the main reasons for disparities in the literature appear to be: the quality of data used, inconsistencies in the lifecycle phase or boundary conditions, the key assumptions made, and the lack of transparency in adopted methodologies. Whilst these issues are well documented in the literature, the rise of embodied carbon tools offer potential solutions. The use of different eco tools is becoming popular in the infrastructure sector, prompting the need to investigate the relevance of those tools for railway LCA studies and how they also address the problems.

\subsubsection{Lifecycle assessment tools in the rail industry}

A search of the literature by the authors revealed a slow adoption of LCA-based tools specifically suited for the rail industry. Most of the tools found did not specifically address rail LCA studies. The Carbon Planning Tool by the UK's Environmental Agency (2016) specifically addressed low carbon planning solutions within flood and coastal risk management. Athena's EcoCalculator (Athena 2018), developed in the North American region was developed primarily for buildings. The Carbon Critical Knowledgebase Tool (Atkins 2010) is a generic global carbon tool suitable for developing mitigation strategies. The asPECT Tool (Wayman et al. 2012) developed in the UK is intended for Asphalt products in the highways sector. The tool which was found to directly address rail LCA studies was the Rail Safety and Standards Board Tool (RSSB 2015). The Rail Carbon Tool (RSSB) is a web-based eco-tool which was developed to help the rail industry understand and reduce its carbon footprint over the whole-of-life cycle of projects by analysing its energy and material use, together with lifecycle costs (RSSB 2015). The tool also permits carbon scenario modelling making it suitable as an LCA optioneering tool. The optioneering capability is enabled by the tool's ability to analyse various lifecycle impact scenarios and to identify carbon hotspots. The tool however permits limited file exchange and integration with intelligible language-structured systems. For example, at the time of preparing this paper, carbon footprints created in project trees within the RSSB tool could only export to csv and pdf formats. It was also reported by Cuenot (2016) that the tool largely ignored rail infrastructure emissions. 


\subsubsection{Lifecycle assessment data needs}

Researchers have attempted to address data quality issues by using LCA data models (Stripple and Uppenberg 2010). However, there is no consensus on how data models should be built up. Both Duan et al. (2015) and Stripple and Uppenberg (2010) found that top-down approaches, which studied the energy and material use, and the emissions and wastes produced were ineffective. These studies promoted bottom-up approaches in scaling up estimates used in LCA assessment since such a technique employed quantity data per local unit making it more flexible and accurate. Access to quality data used for an LCA study by designers could also affect the reliability of the results of the study; but appropriate methodologies needs to make clear what level of data is needed for an LCA study. According to a European Union project of the seventh framework research programme called 'EeBGuide', LCA practitioners have the option of using any of three LCA study types (Wittstock et al. 2012): screening LCA, simplified LCA and Complete LCA. The data quality and quantity increase from lower to higher resolution as the approach moves from a screening LCA study to a complete LCA study. A Screening LCA study is suited for an approximate LCA study (usually in the early design phase while a simplified (or otherwise streamlined) LCA study relies on definitions of the screening LCA study and is suitable for planning purposes since it evaluates additional environmental impact categories. A recent study (Rempelos et al. 2020) adopted the streamlined LCA technique for evaluating the lifecycle impacts of sleeper types in a UK rail network. Finally, a complete LCA study is appropriate for detailed design and covers the full lifecycle of the building or product while adhering to the full ISO 14040/14044 requirements. Formalising railway LCA assessment methodology for a rail component through explicitly stated data exchange transactions could well improve data models as designers are able to specify the required quality and quantity of LCA data and reuse the data models.

\subsection{Need for formalisation of LCA processes in the rail sector}

Although, research in process automations within the rail industry is limited, there is a vast array of researches in other domains on the application of process workflows and the automations of those workflows. It was concluded from the review in the preceding section that formalising railway assessments in railway infrastructure could help designers access high quality data in the early design phase, in addition to re-using the data models which could subsequently lead to more reliable LCA infrastructure studies. In this regard, advanced researches have already been conducted in other domains to model information flow and exchange, the earliest being the use of Integrated Definition for Function Modelling (IDEF0) by Bartley et al. (2016) in a highway project. IDEF0 has a data dictionary and works by modelling the intentions, actions, interactions and activities of a business or project. It is also a computer-generated modelling language with both syntax and semantics. The main draw-back of IDEF0 is its inability to support modern development languages such as the Unified Modelling Language (UML) which therefore limits its interoperability with automated systems. Business process decomposition is underpinned by the principle of Separation of Concerns in Software Engineering (Ghezzi et al. 1991). As applied in other domains, a complex process such as the LCA study of a railway infrastructure needs to be treated as a business concern. To allow its consistent decomposition via the principle of separation of concerns into integral activities, there is need to extract domain knowledge from experts. Researchers (Dasgupta 1991) in knowledge-related business systems have long accepted that the key challenge in the development of knowledge-based systems lies in extracting domain knowledge from experts and laying them out as separated concerns into a representative 
model. This becomes more challenging where the domain area is complicated and disparate in nature (Caetano et al. 2012). This leads directly to the main research question addressed by this paper: how can an integrated platform be developed that could aid structured information and data exchange during the lifecycle analysis of a conventional rail-track by design participants?

\subsection{Mapping infrastructure LCA study with process-based notations}

Following the conclusion that LCA infrastructure study needs to be mapped as a process to enable discretisation of the tasks involved in lifecycle assessments, the authors reviewed existing research in process-based modelling and some of the associated standard tools and standards. It was found that while process workflows have been investigated in other domains such as information management, it remained unexplored within the rail sector. Bartley et al. (2016) who used the IDEF0 technique argued that diagrams with standardised syntaxes and notations were better suited for process descriptions. The usability of executable workflows in Compliant Design Procedures (CDP) was explored by Dimyadi (2016). This implemented a client-server architecture where the Microsoft SQL was used as the server and Camunda BPMN process engine functioned as the client. A survey of the literature revealed that although there were many available process modelling tools, Business Process Model and Notation (BPMN) has emerged as a popular tool for modelling organisational processes and workflows. BPMN which is managed by the Object Management Group (OMG) now has a version 2 release called BPMN 2.0. According to Meidan et al. (2017), BPMN is well apt for process modelling, execution and deployment. The ISO 19650-1 (2018) standard recommends two alternative methodologies: process maps and interaction maps for process modelling. Interaction / transaction maps can also be used to represent the role actors and any information or data exchange (called transactions) between them; this makes it also suitable for use as an organisational process modelling tool for complex BIM-based processes.

\subsection{Embedding LCA with BIM}

There is an increased drive in the infrastructure digital industry to discretise and automate tasks using process modelling tools with an extended focus to deploy the processes within integrated platforms. Alreshidi et al. (2016) developed and deployed a combination of processes and data exchange (using the BPMN engine), and business rule sets (using UML language) to a cloud-enabled BIM environment. Meanwhile, Grefen et al. (2018) integrated business goals with both Internet of Things (IoTs) and a reasoning logic called distributed analysis (DA). The goal was to control physical processes which are both complex but also involves multidisciplinary collaboration. The authors found previous studies within the buildings domain which attempted to integrate BIM with LCA and Life cycle cost analysis (LCCA). For example, Anton and Diaz (2014) first suggested the use of 2 approaches to exploit the capability of BIM: (i) exporting BIM quantity take-off in IFC format to a building database which then combines the result with a life cycle inventory (LCI) database to calculate the LCA; (ii) inclusion of environmental properties in BIM object fields based on LCA estimates. Kylili et al. (2016) employed a systematic approach within the water infrastructure domain by selecting a sustainable option between modern Vernetztes Polyethylen water supply system and two systems made from conventional steel and copper. The selection was accomplished by integrating BIM with LCA approach. 
Similarly, Najjar et al. (2017) also integrated BIM with the LCA methodology in the design phase of a building construction project to facilitate the assessment and selection of alternative building materials (Type A and Type B). Their work identified three levels of LCA tools already in use; 1st level tools applicable in estimating LCA of construction materials (such as SimaPro, GaBi and Open LCA); 2nd level tools suitable for whole building analysis (such as Energy Plus, Ecotect and Green Building Studio) and 3rd level of tools suitable for LCA during construction and use stage and focused on the 3 pillars of sustainability (such as BREEAM, LEED and Green Globes). Their work involved a partial application of the first technique suggested by Anton and Diaz earlier reported. They integrated a BIM tool (Revit) with Green Building Studio and Tally applications (also in Revit) to select a sustainable building material. There is no indication though that their environmental footprint analysis approach was developed in an interoperable format such as the industry foundation class (IFC) which could limit its use by other non-Revit based authoring systems. Despite the popularity of integrated BIM-based lifecycle studies in the buildings domain, there is a dearth of literature in the rail infrastructure domain focused on developing integrated BIM-based lifecycle solutions.

To conclude the review, it is clear the rail industry needs to adopt practices in information science and software engineering to improve the process of conducting LCA studies. There have evidently been more advanced applications of integrated LCA tools in the building domain when compared to the rail infrastructure domain. The initial steps therefore must be geared towards producing digital information in a structured way to permit re-use of whole lifecycle information produced in infrastructure LCA studies. The information also needs to be machine-readable to enable integration with web and BIM-based systems. Thus, the imperative now needs to focus on discretising the process of a railway infrastructure LCA study to remove complexities and lack of consistencies in the data exchanged among the design team. Such efforts will promote the development of LCA optioneering tools that are suitable for carbon scenario modelling, leading to the selection of low carbon solutions.

\section{METHODOLOGY}

\subsection{Scope}

Given the review of the literature, this paper attempted to relate important concepts, synthesise the literature, and advance the knowledge within the railway infrastructure domain. Considering the complexities and lack of clarity involved in infrastructure LCA studies, this paper situated the main research problem and grounded the study within some main foundational concepts. This is crucial for investigating important network of inter-relationships (Berker 1998). Therefore, the paper adopted a conceptual approach and proposes a methodology for quantifying the LCA of a railway infrastructure using an automated workflow. The overall conceptual framework proposes a client / server architecture; however, the process workflow's server architecture is discussed in this paper.

The carbon footprint (CO2-eq) calculator to be used for the study is the Rail Carbon Tool. This tool uses the Inventory of Carbon and Energy (ICE) database for quantifying carbon emission equivalents. As highlighted in the review, the tool has limited interoperability, however, it will be used as the LCA tool in the initial phase of the study (reported in this paper). The selected rail infrastructure which was used for conceptualisation is a conventional rail track. The choice of railway tracks is only for 
demonstration but also for ease of access to data in the subsequent phase of the research. Still, the conceptualisation presented here can apply to any railway sub-component.

\subsection{Conceptual constructs}

The conceptual constructs for the study which was adapted from Hevner et al. (2004) is founded on design science research. Design science as a research paradigm seeks to extend existing frontiers in individual and business competencies in order to create a utility (Hevner et al. 2004). Considering the current study, the utility sought to be created is a process-based LCA for a rail-track. According to design science research, it is critical to fulfil the following seven guidelines (Hevner et al. 2004): 1-design as an artifact, 2define the problem applicability, 3-evaluate the design, 4-provide clear research output, 5-apply research rigor, 6-design effective search process and 7-communicate research. Designing as an artifact requires that the potential solution be able to address a specific business or organisational issue, but this should be done in such a way that the problem can be defined, described and deployed using an Information Technology (IT) solution. An important part of the guideline requires a clear communication of the design-science output to both a technical and non-technical audience. Thus, the solution should be implementable by IT tools and should be easily understood by users (such as management audience) of the information.

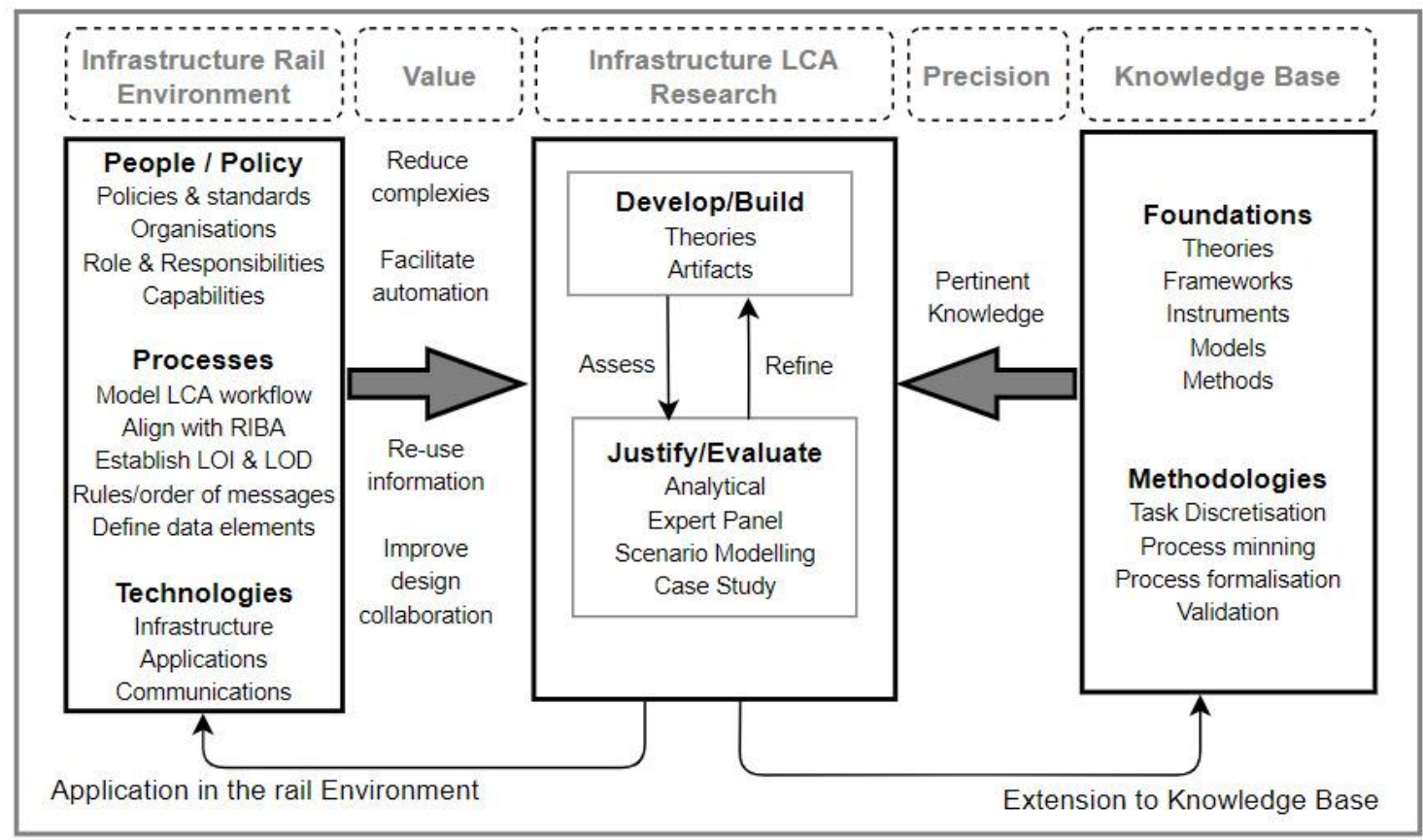

Figure 3.1: Conceptual Framework of the study (based on Hevner et al. 2004)

The conceptual framework for the study is shown in figure 3.1 above and will embed design science guidelines outlined earlier. This is important for conceptualising problems that can be solved using information science strategies. There are three main modules in the conceptual framework (figure 3.1): Environment, Research and Knowledge Base. Dawood and Vukovic (2015) and Succar et al. (2012) identified the core BIM pillars adopted for a whole-of-life construction enterprise and the Environment module has 
been framed thus to align with these. There is a feedforward between the Environment module and the Research module. In addition, there is a feedback between the Research module and the Knowledge Base module. The expected utility (value) for the organisational enterprise provides the feedforward and is in fact the justification for discretising and automating the process of LCA infrastructure studies. This is iterative as the output from the research can constantly lead to improved efficiencies in processes and technologies, including the identification of the appropriate roles and improvement in organisational culture. An important loop in design science framework as shown in figure 3.1 is the opportunity to improve practice and re-use knowledge through the addition to Knowledge Base. Therefore, it created a potential to represent tacit knowledge in a graphical form, making the process transparent and reproducible. The authors found that this was absent in existing LCA methodologies leading to complexities often acknowledged in the literature.

\subsection{Illustration of the conceptual framework using a conventional rail track system}

This paper's main objective was to propose an integrated platform for information and data exchange during the lifecycle analysis of a conventional rail-track. The conceptual framework set out in section 3.2 will be implemented using the conceptual application described for a typical rail track shown in figure 3.2. Data limitation and complexity was always associated with the LCA of a rail component. Therefore, using organisational and design science theories, it was necessary to delineate a railway lifecycle analysis as a business enterprise or project and to systematise the process. Subsequently, the three design science modules (Hevner et al. 2004) namely environment, research and knowledge base will be applied to the LCA process. Core to this framework is the process mining tasks in the environment module. A designer in the appointing party or lead appointed party (ISO 19650-1: 2018) could coordinate this. The process discovery task could also be used to execute goal and scope definition which is the first phase of the ISO 14040/14044 (2006) framework for LCA analysis.

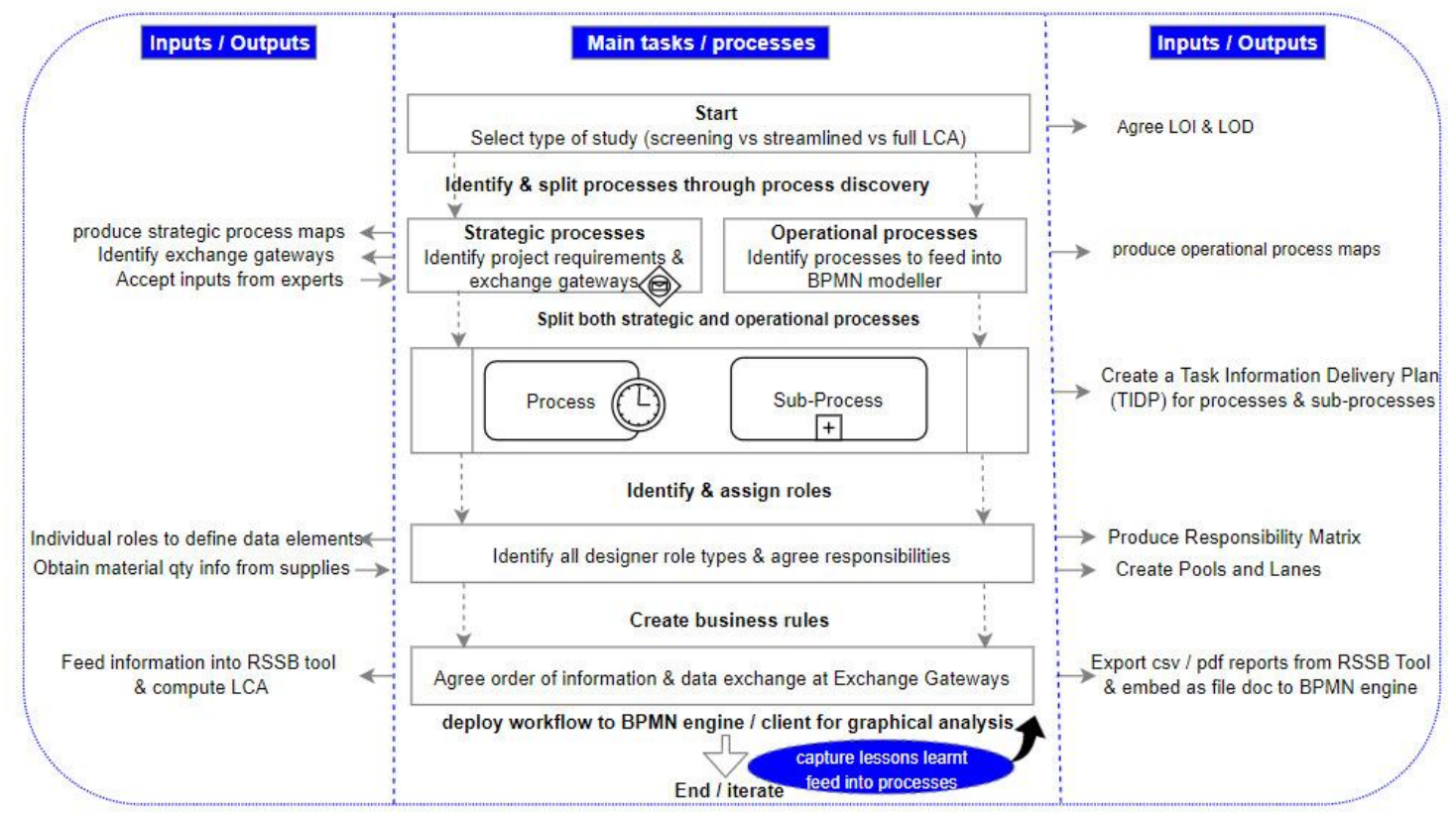

Figure 3.2: Application of the conceptual framework for a rail track 
In order to eliminate inconsistencies related to data collection, the framework recommends that the designers select early on the type of study (screening, streamlined or full LCA) as this will determine the system boundaries, level of information (LOI) and level of detail (LOD) to use throughout the LCA study. The designers might want to consider whether global warming potential (CO2-eq) or additional indicators such as particulate matter (PM10 and PM2.5), Nitrogen oxide (NOx) and non-methane hydrocarbons (NMHC) should be evaluated for the environmental analysis. At the operational level, the BPMN tool can be constantly used to add comments, embed files and documents so that all the designers can have access to information as they are sought. The graphical process workflow thus permits collaborators to regularly assess and refine information in order to improve information and data quality. The end of the workflow allows design practitioners involved in the LCA study to capture and provide a feedback or a feedforward of the lessons learnt from the collaborative production of the LCA information. This may be linked with the interpretation phase of conventional LCA studies.

Regarding the selection of tools and technologies for LCA's, design science reasoning requires that this be decided at the strategic level, before passing to operations. The RSSB rail carbon tool has been selected for use in the automated process workflow. Since the Rail Carbon Tool is only able to produce reports in CSV and pdf formats, the initial input of the lifecycle process automation will be fed into the RSSB and used to calculate the LCA of the rail track while the result from the RSSB tool will be embedded as pdf documents as output from the discipline producing it. Since the process workflow is a graphical tool, the initial LCA results can be viewed by the appropriate project participant which may trigger further analysis and communication with other designers.

\subsection{Architecture of the BPMN workflow for the LCA}

The BPMN application which will be used for the LCA task discretisation is ideal for implementing the principle of separation of concerns (Ghezzi et al. 1991) applied in Software Engineering to split deliverables into processes and sub-processes. This can aid formalisation of the deliverable and reduce subjectivity and inconsistencies. Camunda BPMN was adopted for this process in the study. Camunda BPMN is a proprietary Javabased platform and can support process automation. It has both a community (open source) version and an enterprise version. The illustration presented in this paper was executed with the community version. The platform has three main components (figure 3.3): a process engine, a modeller and a web interface support. 


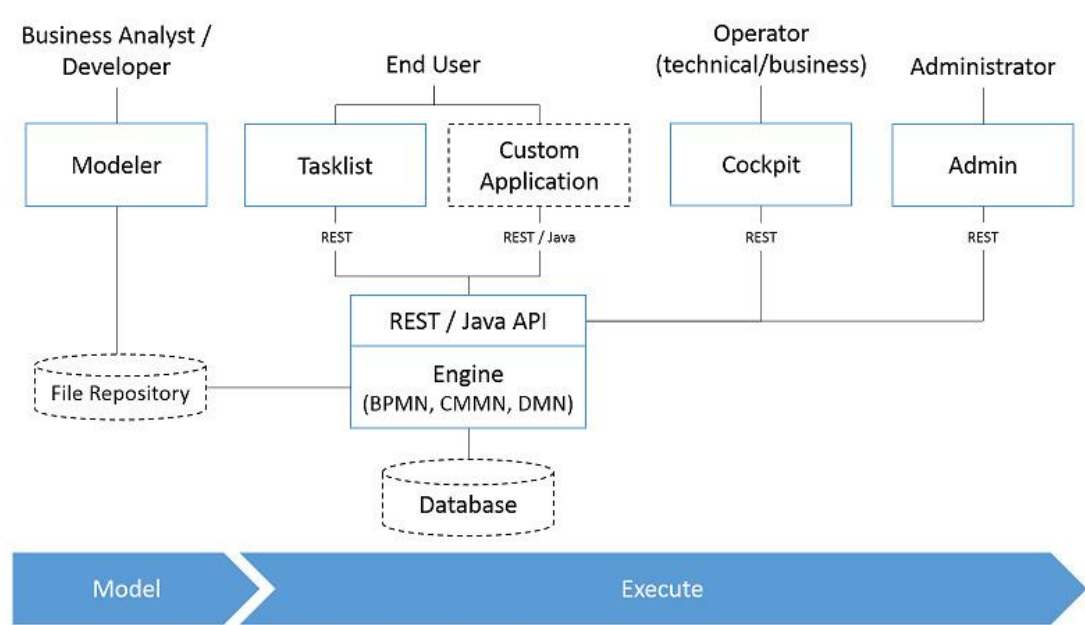

Figure 3.3: Architecture of BPMN process workflow (source: docs.camunda.org/)

Organisation tasks / processes such as those provided in section 3.3 can be modelled in the Camunda Modeller component. However, to automate the processes modelled in Camunda Modeller, a Java Integrated Environment (IDE) called Eclipse was used. It is also an open source software which allows processes to be manipulated using Java delegate implementations. The process applications within the IDE are developed using project templates called Maven. The last component (web interface) creates support for the process workflow to be used on the HTTP protocol via RESTful APIs. Thus, even non-Java developers or designers involved in the lifecycle analysis will be able to create tasks, start processes on the workflow or perform useful analysis.

Once the workflow has been manipulated in code within the IDE, it can be deployed as a Web Application Resource (war) file and opened in Camunda BPMN. Considering guideline 7 (see section 3.2) of the design science theory, the ability to deploy the process workflow to an application server as a war file means that the output of the research (the LCA study) can be communicated in a structured computer language which can be reused and refined. Camunda has a standalone process engine server which should be run on the computer before the web interface is opened. Apache Tomcat 7.12.0 was installed and used for this purpose. Once all the applications have been installed in the local machine, the LCA of the conventional rail track can be assessed in the usual way using the RSSB tool supplemented with a robust process workflow which is provided by the BPMN process engine.

\subsection{Potential integration of the BPMN workflow with level 3 BIM}

There are several ongoing IFC development projects for railway components pioneered by BuildingSmart. Contemporary researches such as Kwon et al (2018) developed extended IFC capability for railway tracks while previous works by Lee et al (2017) extended existing IFC building information by mapping physical and spatial elements to them. Since the creation of the LCA information and data exchanges could be accomplished in a machine-readable format within the BPMN engine, the output can further be integrated with a server such as BIMServers that can support Industry Foundation Class (IFC) files. A key aspect of ongoing IFC development projects is the expansion to the infrastructure domain in IFC5, which will potentially lead to the use of a file neutral format for railway infrastructure projects. 


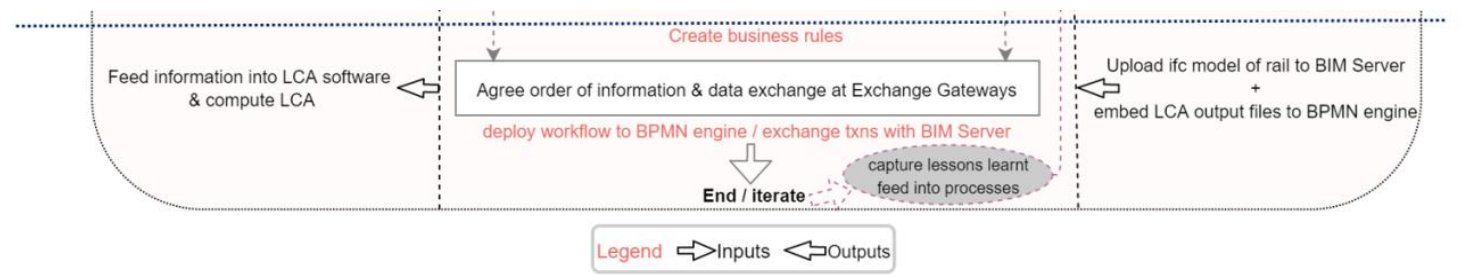

Figure 3.4: Application of the conceptual framework using BIM file-neutral format

This is conceptually illustrated in figure 3.4 under the 'agree order of information and data exchange at exchange gateways' stage. As shown in figure 3.4, an IFC file of a rail track can be embedded as an attachment in the executable BPMN process map. As described in the preceding section, the executable BPMN converts the process map to a war file. Transactions can then be initiated between the IFC file located in the cloud BIMServer (level 3 BIM) and the war file situated in the client BPMN engine using a Globally Unique Identifier (GUID) for communication. For example, a designer can specify the change of a high carbon footprint element such as a specific sleeper type by specifying the attributes that need to be changed in a form and then sending this to the BIMServer. The server then parses the information and returns an embedded IFC model with the updated information.

\section{CONCLUSION, LIMITATION AND FURTHER WORK}

LCA studies in rail systems have been intensively investigated by researchers. This paper identified complexities associated with legacy LCA methodologies in the rail sector. It then proposed a methodology which applied design science technique to facilitate the creation and re-use of information and data in a systematic way within a structured process workflow. The proposed methodology will enable lifecycle information for the rail track to be produced collaboratively in an integrated format. It also allows the created workflow to be deployed to the web where other participants may choose to refine the workflow with additional optioneering solutions. Moreover, since the creation of the LCA information and data exchanges could be accomplished in a machinereadable format within the BPMN engine, the output can further be integrated with a server such as BIM Servers that can support Industry Foundation Class (IFC) files. The process discovery technique employed within the framework could thus promote more researches on IDM developments within the rail sector. Considering that there is now increasing need to digitise the railway infrastructure sector, the limited interoperability of the RSSB Rail Carbon Tool in open BIM platforms highlights the need for tools which can enable sharing of lifecycle information in an integrated way.

A major source of uncertainty in this study is the assumption that it would be technically feasible to initiate and exchange transactions between the client and the BIMServer. Although there are existing open source platforms in use which can facilitate this, the successful execution will depend on the creation of rail track models in an industry-compliant file format. A future work will therefore focus on validating the conceptual model by creating a file neutral IFC model that is based on a conventional rail track in the UK and initiating transactions with the automated process workflows. 


\section{REFERENCES}

Åkerman, J. (2011). The role of high-speed rail in mitigating climate change - The Swedish case Europabanan from a life cycle perspective. Transportation Research Part D: Transport and Environment, 16(3), pp.208-217, https://doi.org/10.1016/j.trd.2010.12.004

Akponeware, A. and Adamu, Z. (2017). Clash Detection or Clash Avoidance? An Investigation into Coordination Problems in 3D BIM. Buildings, 7(4), p.75, https://doi.org/10.3390/buildings7030075

Alreshidi, E., Mourshed, M. and Rezgui, Y. (2016). Cloud-Based BIM Governance Platform Requirements and Specifications: Software Engineering Approach Using BPMN and UML. Journal of Computing in Civil Engineering, 30(4), p.04015063, https://doi.org/ 10.1061/(ASCE)CP.1943-5487.0000539

Andrade, C. and D'Agosto, M. (2016). Energy use and carbon dioxide emissions assessment in the lifecycle of passenger rail systems: the case of the Rio de Janeiro Metro. Journal of Cleaner Production, 126, pp.526-536, https://doi.org/10.1016/j.jclepro.2016.03.094

Antón, L. and Díaz, J. (2014). Integration of Life Cycle Assessment in a BIM Environment. Procedia Engineering, 85, pp.26-32, https://doi.org/10.1016/j.proeng.2014.10.525

Athena (2018). Athena Eco Calculator. [online] Available at: http://www.athenasmi.org/our-software-data/ecocalculator/ [Accessed 6 Jan. 2020].

Atkins (2010). Product information sheet Carbon Critical Buildings. [online] Available at: https://www.atkinsglobal.com/ /media/Files/A/Atkins-

Corporate/group/cr/knowledgebase-product-sheet-final-july10-tcm12-8459.pdf [Accessed 6 Jan. 2020].

Bartley, T., McMahon, C. and Denton, S. (2016). Information flows in highway project delivery. In: 32nd Annual ARCOM Conference, 5- $7^{\text {th }}$ September, [online] Available 
at: https://pdfs.semanticscholar.org/e8ce/fccc0fa57bb8f229859c0c2b93a14ff05e38.pdf [Accessed 8 Jan. 2020].

Bressi, S., Santos, J., Giunta, M., Pistonesi, L. and Lo Presti, D. (2018). A comparative lifecycle assessment of asphalt mixtures for railway sub-ballast containing alternative materials. Resources, Conservation and Recycling, 137, pp.76-88, https://doi.org/10.1016/j.resconrec.2018.05.028

BSI (2016). PAS 2080: Carbon Management in Infrastructure, BSI Standards Limited, London. [online] https://bsol.bsigroup.com/ [Accessed 7 Jan. 2020].

BSI (2011). BS 15978: Sustainability of Construction Works - Assessment of Environmental Performance of Buildings - Calculation Method. [online] https://bsol.bsigroup.com/ [Accessed 7 Jan. 2020].

Becker, H. S. (1998). Tricks of the trade: How to think about your research while you're doing it. Chicago: University of Chicago Press.

Bueno, G., Hoyos, D. and Capellán-Pérez, I. (2017). Evaluating the environmental performance of the high speed rail project in the Basque Country, Spain. Research in Transportation Economics, 62, pp.44-56, https://doi.org/10.1016/j.retrec.2017.02.004

Caetano, A., Silva, A. and Tribolet, J. (2012). Applying the principle of separation of concerns to business process design. International Journal of Organisational Design and Engineering, 2(3), p.250, https://doi.org/10.1504/IJODE.2012.049695

Chester, M., Pincetl, S., Elizabeth, Z., Eisenstein, W. and Matute, J. (2013). Infrastructure and automobile shifts: positioning transit to reduce life-cycle environmental impacts for urban sustainability goals. Environmental Research Letters, 8(1), p.015041, https://doi.org/10.1088/1748-9326/8/1/015041

Chester, M. and Horvath, A. (2009). Environmental assessment of passenger transportation should include infrastructure and supply chains. Environmental Research Letters, 4(2), p.024008, https://doi.org/10.1088/1748-9326/4/2/024008

Cuenot, F. (2016). Carbon Footprint of Railway Infrastructure. Comparing Existing Methodologies on Typical Corridors: Recommendations for Harmonized Approach. [online] Paris: UIC-ETF, pp.5-53. Available at: https://uic.org/IMG/pdf/carbon footprint of railway infrastructure.pdf [Accessed 13 Jan. 2020].

Dalkic, G., Balaban, O., Tuydes-Yaman, H. and Celikkol-Kocak, T. (2017). An assessment of the $\mathrm{CO} 2$ emissions reduction in high speed rail lines: Two case studies from Turkey. Journal of Cleaner Production, 165, pp.746-761, https://doi.org/10.1016/j.jclepro.2017.07.045

Dasgupta, S. (1991). The Nature of Design Problems: In Design Theory and Computer Science. Cambridge: Cambridge University Press, pp.13-35.

Dawood, N. and Vukovic, V. (2015). Whole Lifecycle Information Flow Underpinned by BIM: Technology, Processes, Policy and People. In: 2nd International Conference on Civil and Building Engineering Informatics, 22-24 ${ }^{\text {th }}$ April, [online] Available at: https://pdfs.semanticscholar.org/af4a/782fa0d8d3da789ea463349b876387b43987.pdf

[Accessed 13 Jan. 2020]

De Martinis, V. and Corman, F. (2018). Data-driven perspectives for energy efficient operations in railway systems: Current practices and future opportunities. Transportation Research Part C, 95, pp.679-697, https://doi.org/10.1016/j.trc.2018.08.008

Del Pero, F., Delogu, M., Pierini, M., Bonaffini, D. (2015). Life Cycle Assessment of a heavy metro train, Journal of Cleaner Production,87(1), pp. 787-799, https://doi.org/10.1016/j.jclepro.2014.10.023 
Dietz, J. (2006). Enterprise Ontology: Theory and Methodology. Berlin: Springer.

Dimyadi, J. (2016). Automated Compliance Audit Processes for Building Information Models with an Application to Performance-Based Fire Engineering Design Methods. $\mathrm{PhD}$. The University of Auckland.

Duan, H., Hu, M., Zhang, Y., Wang, J., Jiang, W., Huang, Q. and Li, J. (2015). Quantification of carbon emissions of the transport service sector in China by using streamlined life cycle assessment. Journal of Cleaner Production, 95, pp.109-116, https://doi.org/10.1016/j.jclepro.2015.02.029

EN ISO 14040 (2006). Environmental Management - Life cycle assessment - Principles and framework. [online] Available at: https://www.iso.org/standard/37456.html [Accessed 6 Jan. 2020].

EN ISO 14044 (2006). Environmental Management - Life cycle assessment Requirements and guidelines. [online] Available at: https://www.iso.org/standard/38498.html [Accessed 6 Jan. 2020].

Environment Agency (2016). Carbon Planning Tool. [online] Available at: https://www.gov.uk/government/uploads/system/uploads/attachment data/file/57170 7/LIT 7067.pdf [Accessed 10 Jan. 2020].

Esters, T. and Marinov, M. (2014). An analysis of the methods used to calculate the emissions of rolling stock in the UK. Transportation Research Part D: Transport and Environment, 33, pp.1-16, https://doi.org/10.1016/j.trd.2014.08.012

Facanha, C. and Horvath, A. (2006). Environmental Assessment of Freight Transportation in the U.S. (11 pp). The International Journal of Life Cycle Assessment, 11(4), pp.229-239, https://doi.org/10.1065/lca2006.02.244

Ghezzi, C., Mandrioli, D. and Jazayeri, M. (1991). Fundamentals of Software Engineering. Englewood Cliffs, NJ: Prentice-Hall.

Grefen, P., Ludwig, H., Tata, S., Dijkman, R., Baracaldo, N., Wilbik, A. and D’Hondt, T. (2018). Complex Collaborative Physical Process Management: A Position on the Trinity of BPM, IoT and DA. IFIP Advances in Information and Communication Technology, pp.244-253, https://doi.org/10.1007/978-3-319-99127-6_21

Hauschild, M., Jeswiet, J. and Alting, L. (2005). From Life Cycle Assessment to Sustainable Production: Status and Perspectives. CIRP Annals, 54(2), pp.1-21, https://doi.org/10.1016/S0007-8506(07)60017-1

Hevner, A., March, S., Park, J. and Ram, S. (2004). Design Science in Information Systems Research. MIS Quarterly, 28(1), https://dl.acm.org/doi/10.5555/2017212.2017217

HM Treasury (2013). Infrastructure Carbon Review: Technical Report. [online] Available at: $\quad$ https://www.gov.uk/government/publications/infrastructure-carbon-review [Accessed 10 Jan. 2020].

Hoogervorst, J. (2018). Practicing Enterprise Governance and Enterprise Engineering: Applying The Employee-Centric Theory of Organization. Springer, Cham.

ISO 19650-1 (2018). Organization of information about construction works -Information management using building information modelling - Part 1: Concepts and principles, [online] Available at: https://bsol.bsigroup.com/ [Accessed 7 Jan. 2020].

Jackson, D. and Brander, M. (2019). The risk of burden shifting from embodied carbon calculation tools for the infrastructure sector. Journal of Cleaner Production, 223, pp.739-746, https://doi.org/10.1016/j.jclepro.2019.03.171

Jehanno, A., Palmer, D., \& James, C. (2011). High speed rail and sustainability. [online] Available at: https://trid.trb.org/view/1128154 [Accessed 14 Jan. 2020]. 
Kaewunruen, S. and Lian, Q. (2019). Digital twin aided sustainability-based lifecycle management for railway turnout systems, Journal of Cleaner Production, 228, pp. 1537-1551, https://doi.org/10.1016/j.jclepro.2019.04.156

Krezo, S., Mirza, O., Kaewunruen, S. and Sussman, J. (2018). Evaluation of CO2 emissions from railway resurfacing maintenance activities. Transportation Research Part D: Transport and Environment, 65, pp.458-465, https://doi.org/10.1016/j.trd.2018.09.019

Kwon, T., Park, S., Seo, K. and Lee, S. (2018). The Information Modeling Method based on Extended IFC for Alignment-based Objects of Railway Track. Journal of the Computational Structural Engineering Institute of Korea, 31(6), pp.339-346, https://doi.org/10.7734/COSEIK.2018.31.6.339

Kylili, A., Fokaides, P., Vaiciunas, J. and Seduikyte, L. (2016). Integration of Building Information Modelling (BIM) and Life Cycle Assessment (LCA) for sustainable constructions. Journal of Sustainable Architecture and Civil Engineering, 4(13), pp.28-38, https://doi.org/10.5755/j01.sace.13.4.12862

Lee, S., Park, S., Kwon, T. and Seo, K. (2017). Civil Infrastructure Information Modeling Method Based on Extended IFC Entities using BIM Authoring Software. Journal of the Computational Structural Engineering Institute of Korea, 30(1), pp.77-86, http://dx.doi.org/10.7734/COSEIK.2017.30.1.77

Meidan, A., García-García, J., Escalona, M. and Ramos, I. (2017). A survey on business processes management suites. Computer Standards \& Interfaces, 51, pp.71-86, https://doi.org/10.1016/j.csi.2016.06.003

Meynerts, L., Gotze, U., Claus, S., Pecas, P. and Ribeiro., I. (2017). Concept of Integrated Life Cycle Assessment and Costing - Application to the Case of Designing a Hybrid Train. Procedia CIRP, 61, pp.744-749, https://doi.org/10.1016/j.procir.2016.11.241

Najjar, M., Figueiredo, K., Palumbo, M. and Haddad, A. (2017). Integration of BIM and LCA: Evaluating the environmental impacts of building materials at an early stage of designing a typical office building. Journal of Building Engineering, 14, pp.115-126, https://doi.org/10.1016/j.jobe.2017.10.005

Ortega, A., Blainey, S. and Preston, J. (2018). Assessing Whole-Life Carbon Footprint of Under Sleeper Pad Installation for Ballasted Track, Journal of Transportation Engineering, Part A: Systems, 144(12), p.04018073, https://doi.org/10.1061/JTEPBS.0000192

Ortmeyer, T. and Pillay, P. (2001). Trends in transportation sector technology energy use and greenhouse gas emissions. Proceedings of the IEEE, 89(12), pp.1837-1847, https://doi.org/10.1109/5.975921

Poon, C. (2007). Reducing construction waste. Waste Management, 27(12), pp.1715-1716, https://doi.org/10.1016/j.wasman.2007.08.013

Pritchard, J. and Preston, J. (2018). Understanding the contribution of tunnels to the overall energy consumption of and carbon emissions from a railway. Transportation Research Part D: Transport and Environment, 65, pp.551-563, https://doi.org/10.1016/j.trd.2018.09.010

Rempelos, G., Preston, J. and Blainey, S. (2020). A carbon footprint analysis of railway sleepers in the United Kingdom. Transportation Research Part D: Transport and Environment, 81, p.102285, https://doi.org/10.1016/j.trd.2020.102285

Rocha, A., Araújo, A., Carvalho, A. and Sepulveda, J. (2018). A New Approach for Real Time Train Energy Efficiency Optimization. Energies, 11(10), pp.2660, https://doi.org/10.3390/en11102660 
RSSB (2015). Rail Carbon Tool User Guides. [online] Available at: https://www.rssb.co.uk/Library/improving-industry-performance/2017-02-userguide-rail-carbon-tool.pdf [Accessed 7 Jan. 2020].

Saxe, S., Casey, G., Guthrie, P., Soga, K. and Cruickshank, H. (2016). Greenhouse gas considerations in rail infrastructure in the UK. Proceedings of the Institution of Civil Engineers - Engineering Sustainability, 169(5), pp.171-180, https://doi.org/10.1680/jensu.15.00015

Shin, Y. and Cho, K. (2015). BIM Application to Select Appropriate Design Alternative with Consideration of LCA and LCCA. Mathematical Problems in Engineering, pp.114, https://doi.org/10.1155/2015/281640

Stripple, H. and Uppenberg, S. (2010). Life Cycle Assessment of Railways and Rail Transports - Application in Environmental Product Declarations (EPDS) for the Bothnia Line. Stockholm: IVL Swedish Environmental Research Institute, [online] Avalaible https://www.ivl.se/download/18.343dc99d14e8bb0f58b75d4/1445517456715/B1943.pd f [Accessed 15 Dec. 2019].

Succar, B., Sher, W. and Williams, A. (2012). Measuring BIM performance: Five metrics. Architectural Engineering and Design Management, 8(2), pp.120-142, https://doi.org/10.1080/17452007.2012.659506

Wayman, M., Mellor, I., Cordell, B., James, D., Gossling, R., Loveday, C., Simms, M. and Southwell, C. (2012). The Asphalt Pavement Embodied Carbon Tool (asPECT): Developing a Carbon Footprinting Methodology for Asphalt Products. In: 5th Eurasphalt \& Eurobitume Congress, 13-15 ${ }^{\text {th }}$ June, [online] Available at: https://pdfs.semanticscholar.org/0a65/41d5030c2086472258221de816e5d1fe11a3.pdf [Accessed 19 Dec. 2019].

Westin, J. and Kågeson, P. (2012). Can high speed rail offset its embedded emissions? Transportation Research Part D: Transport and Environment, 17(1), pp.17, https://doi.org/10.1016/j.trd.2011.09.006

Wong, J. and Zhou, J. (2015). Enhancing environmental sustainability over building life cycles through green BIM: A review. Automation in Construction, 57, pp.156-165, https://doi.org/10.1016/j.autcon.2015.06.003

Wittstock, B., Gantner, J., Lenz, K., Saunders, T., Anderson, J., Carter, C., Gyetvai, Z., Kreißig, J., Braune, A., Lasvaux, S., Bosdevigie, B., Bazzana, M., Schiopu, N., Jayr, E., Nibel, S., Chevalier, J., Hans, J., Fullana-i-Palmer, P., Gazulla, C., Mundy, J.-A., Barrow-Williams, T., Sjostrom, C. (2012). EeBGuide Guidance Document - Part B: Buildings European Commission(2012), pp. 1-360. [ONLINE] Available at: https://www.eebguide.eu/eebblog/wp-content/uploads/2012/10/EeBGuide-B-FINALPR 2012-10-29.pdf [Accessed 10 Jan. 2020]. 